\title{
Structural-Semantic Analysis of English Proverbs with "Smile"
}

\author{
Stella Israyelyan \\ Gyumri State Pedagogical Institute
}

D hraseology is a kind of a picture gallery in which are collected vivid and amusing sketches of the nation's customs, traditions and prejudices, recollections of its past history, scraps of folk songs and fairy-tales. Phraseological units or idioms as they are called by most scholars, represent what can probably be described as the most picturesque, colorful and expressive part of the language vocabulary.

In his "Book of English Idioms" V.H. Collins writes: "In standard spoken and written English today idiom is an established and essential element that, used with care, ornaments and enriches the language" (1958:23).

According to Rosemarie Glaeser, a phraseological unit is a lexicalized, reproducible bilexemic or polylexemic word group in common use, which has relative syntactic and semantic stability, may be idiomatized, may carry connotation, and may have an emphatic or intensifying function in a text (Glaeser 1998).

Most scholars today accept the semantic criterion of distinguishing phraseological units from free word-groups as a major approach and base their research work in the field of phraseology on the definition of a phraseological unit offered by Professor A.V. Koonin, the leading authority on problems of English phraseology. Prof. Koonin defines phraseological units as stable word-groups with partially or fully transferred meanings (Koonin 1996).

Proverbs which are popular sayings containing advice or stating a generally accepted truth represent one type of idiom proper and form a big group within the system of idioms of the English language. English is particularly rich in proverbs - those modes of expression peculiar to a language (or dialect) which frequently defy logical and grammatical rules. Without proverbs English would lose much of its variety and humor both in speech and writing.

The question of whether or not proverbs should be regarded as a subtype of phraseological units and studied together with the phraseology of a language is a controversial one. We share A.V. Koonin's opinion and state that proverbs and sayings must be studied on word level. Professor Koonin labels proverbs communicative phraseological units (Koonin 1996) which are very short, just to the point; bear a complete thought and ideology and can't be analysed on the same level as a sentence.

To make the respective statement more general, it must be stated that most proverbs are based on a metaphor. Further typical features of the proverb include shortness (average seven words), and the fact that its author is generally unknown (otherwise it would be a quotation).

Because most proverbs have their origin in oral tradition, they are generally worded in such a way as to be remembered easily and tend to change little from generation to generation, so that sometimes their specific meaning is no longer relevant.

Proverbs function as "folk wisdom", general advice about how to act and live. And 
because they are folk wisdom, they often strongly reflect the cultural values and physical environment from which they arise. For instance, island cultures such as Hawaii, have proverbs about the sea; Eastern cultures have proverbs about elephants, and American proverbs, many collected and published by Benjamin Franklin, are about hard work bringing success. Proverbs are used to support arguments, to provide lessons and instructions, and to stress shared values.

Wolfgang Mieder writes: "A proverb is a short, generally known sentence of the folk which contains wisdom, truth, morals, and traditional views in a metaphorical, fixed and memorizable form and which is handed down from generation to generation" (Mieder 1985:119).

In this paper we shall dwell upon the proverbs that contain the word "smile" and we'll analyze them from a semantic, grammatical-structural and stylistic angles.

Semantically the "smile proverb" can be divided into groups which indicate love, kindness, friendship, life philosophy, comparative meaning and so on. Below are examples of proverbs belonging to the mentioned groups:

\section{Life Philosophy}

A Smile is a curve that sets everything straight.

Life is short but a smile takes barely a second.

One who smiles rather than rages is always the stronger.

The man who gives little with a smile gives more than the man who gives much with a frown.

It's better to make the world smile at what you say than laugh at what you do.

Don't cry because it's over, smile because it's happened.

If you have made another person on this earth smile, your life has been worthwhile.

People seldom notice old clothes if you wear a big smile.

\section{Friendship}

Wear a smile and have friends, wear a scowl and have wrinkles.

If you see a friend without a smile, give him one of yours.

\section{Kindness and Love}

Every time you smile at someone; it is an action of love, a gift to that person, a beautiful thing. all.

There are hundreds of languages in the world, but a smile speaks them

A warm smile is the universal language of kindness.

Remember that there is no happiness in having and getting, but only in giving. Reach out. Smile. Hug!

A smile is a language that even a baby understands.

Smile; it is the second best thing one can do with one's lips. 


\section{Comparative Meaning}

If you're not using your smile, you're like a man with a million dollars in the bank and no checkbook.

A smile abroad is often a scowl at home.

On the grammatical level we analyse sentences in accordance to their communicative types, i.e. narrative that falls into affirmative and negative, exclamatory and interrogative sentences. This concerns not only the simple sentence but also the complex one. Which parts of speech appear more frequently in a proverb is also considered to be an aspect of grammatical approach. The word "smile" is often used in subordinate clauses of time, condition, etc. The data at our disposal show that "smile" is more often patterned in the frame of affirmative sentences.

\section{A laugh is a smile that bursts.}

When you were born, you were crying and everyone around you was smiling. Live your life so that when you die, you're the one smiling and everyone around you is crying.

If you're not using your smile, you're like a man with a million dollars in the bank and no checkbook.

If a man smiles all the time, he's probably selling something that doesn't work.

If you have made another person on this earth smile, your life has been worthwhile.

If you don't have anything nice to say, just smile!

Our analysis reveals an equal percentage use of nouns and verbs. As to the verb forms, we can state that a bare infinitive is used more often than gerundial forms. The sentences are mainly patterned with the active constructions; not a single passive construction has been found.

Keep walking and keep smiling.

Don't worry! Be happy! Keep smiling!

Proverbs can also be analysed on the stylistic level. In this case we dwell on (1) the phonetic expressive means such as alliteration, assonance, rhyme, etc.; and (2) stylistic devices such as repetition and comparison.

Alliteration is a phonetic stylistic device which aims at imparting a melodic effect to the utterance. The essence of this device lies in the repetition of similar sounds, in particular consonant sounds.

A smile is a curve that sets everything straight.

$\underline{S}$ mile, even if it's a sad smile, because $\underline{s} a d d e r$ than a sad smile is the sadness of not knowing how to smile. 
One who smiles rather than rages is always the stronger.

Keep walking and keep smiling.

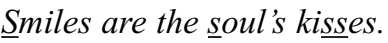

Smile and the world smiles with you. Cry and you cry alone.

Therefore alliteration is generally regarded as a musical accompaniment of the author's idea, supporting it with some vague emotional atmosphere which each reader interprets for himself.

Assonance is the repetition of vowel sounds in non-rhyming words. Assonance is neither a consonance and nor an alliteration. It doesn't have to rhyme and if it does, it is only the vowels that rhyme. Assonance is more a feature of verse than prose.

Smile, light the way and have a great day!

Wear a smile and have friends, wear a scowl and have wrinkles.

A smile abroad is often a scowl at home.

A smile is a light in the window of the soul indicating that the heart is at home.

Smile and the world smiles with you. Cry $\underline{\text { and }}$ you cry alone.

Rhyme is the repetition of identical or similar terminal sound combinations of words. Rhyming words are generally placed at a regular distance from each other. In verse they are usually placed at the end of the corresponding lines. We distinguish several types of rhyme, among which the masculine rhyme: a rhyme in which the stress is on the final syllable of the words;

If you have made another person on this earth smile, your life has been worthwhile.

A smile abroad is often a scowl at home.

In the feminine rhyme the stress is on the penultimate (second from last) syllable of the words;

A winning smile makes winners of us all.

Repetition is an expressive means of language used when the speaker is under the stress of strong emotion. It shows the state of mind of the speaker. When used as a stylistic device, repetition acquires quite different functions. It does not aim at making a direct emotional impact. On the contrary, the stylistic device aims at logical emphasis, an emphasis necessary to fix the attention of the reader on the key-word of the utterance.

Wear a smile and have friends, wear a scowl and have wrinkles.

Keep walking and keep smiling. 
Smile, even if it's a sad smile, because sadder than a sad smile is the sadness of not knowing how to smile.

The man who gives little with a smile gives more than the man who gives much with a frown.

$\underline{\text { Smile }}$ and the world smiles with you. Cry and you cry alone.

Antonymous pairs are also frequently used in the proverbs with the constituent "smile". It makes the message of the proverb more emphatic and impressive.

A smile abroad is often a scowl at home.

If you're not using your smile, you're like a man with a million dollars in the bank and no checkbook.

It takes 26 muscles to smile, and 62 muscles to frown.

One who smiles rather than rages is always the stronger.

The man who gives little with a smile gives more than the man who gives much with a frown.

It's better to make the world smile at what you say than laugh at what you do.

A smile is as nice to give as it is to receive.

$\underline{\text { Smile }}$ and the world smiles with you. $\underline{\text { Cry }}$ and you cry alone.

As a conclusion we can state that proverbs are widely used in the society on a regular basis. Some scholars and popular writers have claimed repeatedly that proverbial language has passed from usage. However, it remains an easily proven fact that proverbs are not "passed" and definitely not dead. This form of language helps to express our thoughts more exactly and vividly. Proverbs contain wisdom, humor, and usually fit many purports.

Proverbs have not lost their well-established popularity, and they continue to be everpresent even in a modern technological society.

\section{References:}

1. Collins, V.H. (1958) A Book of English Idioms with Explanations. London: Longman.

2. Galperin, I.R. (198) Stylistics. Moscow: Vishaya Scola.

3. Glaeser, R. (1998) The Stylistic Potential of Phraseological Units in the Light of Genre Analysis. Oxford: Clarendon Press.

4. Koonin, A.V. (1996) A Course of Phraseology of Modern English. Moscow: Vishaya Scola.

5. Miede, W. (1993) Proverbs are Never out of Season. New York: Oxford Universitty Press.

6. Vinogradov, V.V. (1978) On the Main Types of Phraselogical Units in Russian. Leningrad. 
7. Vinogradov, V.V. (1978) Selected Works. The History of Russian Language. Moskow: Nauka.

8. A Dictionary of American Proverbs (1992) New York: Oxford University Press.

9. The Oxford Dictionary of English Proverbs. (1970) London: OUP, Ely House.

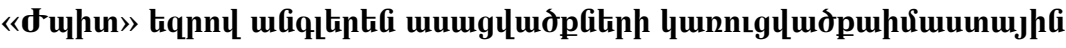 lthpnıdnıpjnıG}

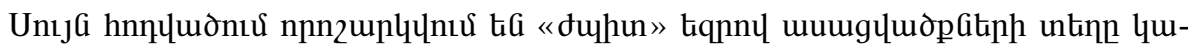

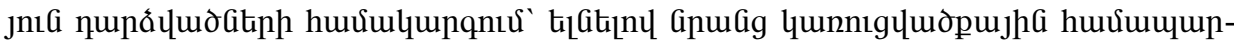

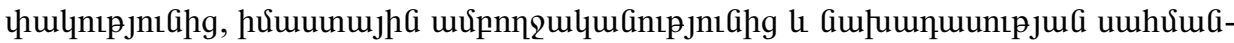

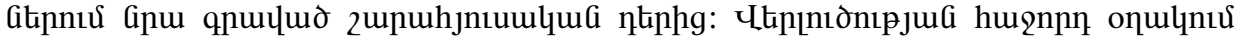

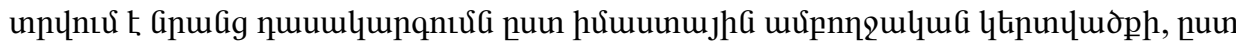

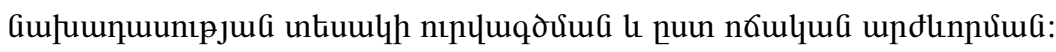

